\title{
Children with Autism in the 21st Century: Problems with Socialization at a Preschool Age
}

\author{
Irina A. Nigmatullina*(a), Viktoria Y. Dadakina (b)
}

(a), (b) Kazan Federal University, 420008, Kazan (Russia), 18 Kremlyovskaya street

\begin{abstract}
The issues that modern researches on autism currently explore are quite diverse: starting with studying the features of the psychophysical development and individual capabilities of children with autism spectrum disorders and ending with the development of new models of timely comprehensive correction of developmental disorders and social adaptation of people who belong to this category. The purpose of the study is to contour special educational needs of children with autism which impede their successful socialization. The study involved content analysis of modern researches conducted by leading experts in the field of autism devoted to the study of autism phenomenon, identification and refinement of diagnostic criteria for autism spectrum disorders, and determination of the effectiveness of integrated models of support for children with autism. The analysis helped to reveal polymorphism of views and directions in the study of the features of autism manifestations. The analysis allowed to clarify the existing knowledge concerning the three-component model of autism which includes disorders in communication and speech, behavior and socialization, as well as knowledge concerning the peculiarities of mental development of children with autism. The study explored the main tools of modern diagnostic examinations and described the variable models of education and upbringing of children with ASD. The data presented in the article make it possible to determine psychological and pedagogical conditions of socialization of children with autism.
\end{abstract}

Keywords: autism; socialization; preschool children; autistic development model.

(C) 2019 Irina A. Nigmatullina, Viktoria Y. Dadakina

This is an open access article distributed under the terms of the Creative Commons Attribution License (CC BY 4.0), which permits unrestricted use, distribution, and reproduction in any medium, provided the original author and source are credited.

Published by Kazan federal university and peer-reviewed under responsibility of IFTE-2019 (V International Forum on Teacher Education) 


\section{Introduction}

Clinical and psychopathological characteristics of autism are well described by Russian and foreign researchers (Mnukhin, Zelenskaya, \& Isaev, 1967; Isaev \& Kagan, 1973; Schmidt, 1978; Wing, 1981; Rutter, 1985; Schopler \& Mesibov, 1988; Schopler, Short, \& Mesibov, 1988; Schopler, Van Bourgondien, \& Bristol, 1993; Bashina, Krasnoperova, \& Simashkova, 2003; Simashkova, 2006; Medvedev, 2011; Kagan, 2015; Mikirtumov \& Zavitaev, 2012) At the same time, it still remains unclear what determines this community both from psychopathological and pathogenetic positions (Tiganov \& Bashina, 2005). The beginning of the study of the phenomenon of "autism", which is now the subject of a comprehensive study of a number of sciences, is found in psychopathology. Psychopathological approach suggests that this concept is considered as a central symptom for severe violations of interaction of a person with reality. The largest number of studies on the manifestations of autism in children was conducted within the framework of studying childhood schizophrenia, psychosis, and disorders based on organic damages or underdevelopment of the central nervous system. Autism is a specific clinical syndrome with a characteristic developmental disorder of the psyche and its main feature is mental loneliness, which ignores everything that happens from the outside. Mikirtumov \& Zavitaev (2012, p.142) considered autism as "an isolation of associations from experience, ignoring real relationships", identified three main components of the autistic structure: loss of contact with reality, "life in an imaginary world of fulfilled desires and persecution ideas" and a different constellation of the autistic and real worlds.

\section{Purpose and objectives of the study}

At the current stage, early childhood autism is considered to be one of the most complicated types of mental development disorders, which belongs to the group of complex disorders and manifests itself in a comprehensive developmental disorder of the psyche: cognitive, emotional and sensory spheres. Modern studies of autism are aimed at exploring the peculiarities of psychophysical development and individual capabilities of children with autism and studying foreign and Russian experience and developing new models of timely comprehensive support and social adaptation of people belonging to this category. Our analysis helped to reveal polymorphism of views and directions in the study of the features of autism manifestation, in the effectiveness of modern diagnostic examination tools and correction methods, in the effectiveness of the implementation of variable models of education and upbringing of children with autism.

Currently, one of the most significant and controversial issues of studying autism are the issues related to the differential diagnosis of autistic conditions of various origins, to the study of the mental development of children with its various forms of manifestation, as well as to the identification of effective practices for accompanying and socializing children with autism

The purpose of the study is determined by the need to highlight the contour of the special educational needs of children with autism which hinder their successful socialization.

\section{Literature review}

Kanner (1943) formulated and approved in science the concept of a specific developmental disorder called autism, considering it as a disorder of affective communication and designating this phenomenon as "infantile autism" which reveals itself already in the early childhood. He singled out the specific features of the clinical picture of early childhood autism, such as "extreme autistic loneliness" and 
related social developmental disorders: inability to tune in to adequate behavior, delay or deviation in speech development with echolalia and improper use of pronouns, monotonous repetition of the noise or words, excellent mechanical memory, limited range of spontaneous activity, stereotypy, the desire to keep everything intact, fear of change and incompleteness, rituals, the appearance of strange activities, highly focused, intense passions and fixations and pathological relationships with others, desire to communicate with inanimate objects. He considered autism as a mental disorder which reflects improper upbringing, alienation of a child by an indifferent mother, describing autistic manifestations as a defensive mechanism. H. Asperger considered autism as autistic psychopathy. He noted unusually early "unnatural" speech development (often even before the kid starts to walk), peculiar use of language, unusual intonation of speech, word creation, inability to make a full-fledged visual contact. He pointed out the poverty of facial expressions and gestures, motor awkwardness, disharmonious, angular movements, lack of the simplest social skills, impulsiveness of children, without taking into account the requirements of the situation. In games and hobbies, such children prefer stereotyped, habitual actions. Speaking about the nature of autism, H. Asperger pointed out the biological defect of affective contact (in prenatal or natal period), and also came to the conclusion that autistic psychopathy is a hereditary disease. In prognostic terms, Asperger syndrome is considered as a better "version" of autism compared to Kanner syndrome. The organic nature of autism has been described by Mnukhin, Zelenetsky, \& Isaev (1967) who believed that the cause of child autism may hide in special organic failure of the central nervous system.

Kagan (2015) considered autism as a congenital state of developmental distortion which manifests itself primarily by the limitations and characteristics of communication and social contacts. The lack of communication is formed on the basis of primary structural disorders or uneven development of the prerequisites of communication and the secondary loss of the regulatory impact of communication on thinking and behavior. The scientist understood the difficulties of communication as the impossibility of adequate perception and interpretation of information, insufficiency and inadequacy of expressive means of communication, violation of mutual understanding with its regulating influence on thinking and behavior, impossibility of adequate planning and flexible variation of behavior and choosing the method and style of communication.

Thus, the analysis of various methodologies, scientific schools, basic theoretical models and conceptual approaches to the definition of the "autism" phenomenon allowed us to expand the scientific content of this concept.

\section{Methodology}

The study involved content analysis of modern research works by leading experts in the field of autism research, devoted to the study of the autism phenomenon, to the identification of diagnostic criteria for autism spectrum disorders, and to the effectiveness of the integrated support models for children with autism that have been developed in domestic and foreign practice.

\section{Results}

The importance of this issue is emphasized by many domestic and foreign researchers and is determined by the need to develop therapeutic and psychological-pedagogical correctional strategies for each specific case based on the knowledge of core manifestations of autism as a distorted mental development and knowledge of the stages of normal mental development of children. According to Kagan (2015), the importance of differential diagnosis is determined by the fact that children with autistic 
manifestations belong to a group of people with increased risk of developing schizophrenia. Therefore, the emphasis should be placed on early diagnosis aimed at differentiating autism from autism syndromes in other diseases and mental underdevelopment (Kagan, 2015).

Scientific studies present various approaches to the classification of early childhood autism and conditions similar to it. Issues of differential diagnosis of autism are well described in the studies of Mnukhin, Zelenetsky, \& Isaev (1967), Kagan (2015) and others where autism is described differentially in schizophrenia and other diseases.

Domestic and foreign authors differentiate autism syndrome in different clinical structures. Asperger (1968) identified it in early childhood autism (Kanner syndrome), schizophrenia, oligophrenia, hearing impairment, autistic psychopathy (currently referred to as Asperger syndrome). Sukhareva (1974) and Bashina (1999) consider it as a part of the early schizophrenic process. Kagan (1981) distinguishes autism in schizophrenia, schizoid psychopathy, residual organic childhood autism, and para-autistic reactions of a neurotic nature. Nissen, Willingham, \& Hartman (1989) talk about autism (Kanner syndrome) caused by a damage of the central nervous system in the prenatal period in combination with a hereditary factor, about autistic psychopathy (Asperger syndrome) with a hereditary radical, somatogenic autism as a result of severe organic brain damage, about psychogenic autism caused by a factor of prolonged emotional frustration.

Wing (1981) identified disorders that manifest themselves in the absence or violation of bilateral social interaction; the absence or violation of comprehension and use of language - non-verbal as well as verbal ones; and in the absence or violation of a truly flexible creative activity, with its replacement for a narrow circle of repetitive, stereotypical activities. She introduced the concept of "the triad of disorders in autism". Each aspect of this triad can manifest itself with varying degrees of severity and can be associated with any level of intelligence measured by standard tests. She divided all autistic children according to their skills of entering social contacts into "lonely" (not entering into communication), "passive" and "active, but ridiculous". She associated the best prognosis with "passive" type of children.

Summarizing and analyzing clinical experience, Rutter (1985) formulated the criteria for expressed forms of child autism: profound impairments in social development, delay and impaired development of speech out of touch with the intellectual level, the desire for constancy, which manifests itself in stereotypes, super-addiction to objects and resistance to environmental changes, the occurrence of violations up to 30 months.

Lebedinskaya, Nikolskaya, \& Baenskaya (2007) identified four main groups of early childhood autism. The main criterion that they chose for division was the nature and the extent of violations of interaction with the external environment. Children of the first group are characterized by an increased detachment from the surrounding world with a predominance of autistic substitution of the surrounding sounds, super-retardation in relations with the surrounding environment, with the presence of field behavior, mutism, and lack of the need for verbal contacts. These manifestations allowed the authors to qualify this type of autistic dysontogenesis as regressive one. From nosological point of view, here we are talking more about the malignant schizophrenia. Children of the second group are characterized by rejection of the world in the form of autostimulation and rejection of the external environment, as the leading pathopsychological syndrome, which manifests itself in increased sensitivity to external stimuli, in the obsession with motor, sensory, speech stereotypy, impulsive actions; in demanding the stereotypical habitat; in the presence of numerous fears of hypersensitive nature; in an autonomous game involving nonplayable items, in clearly expressed violations of the sense of self-preservation, the "phenomenon of 
identity", in symbiotic relationship with mother, and also often in a lag in mental development. This type of childhood autism may occur due to both schizophrenia and organic damage of the central nervous system. The third group, according to the researchers, is characterized by the prevalence of autistic substitution of the surrounding with supervaluable addictions, by special, abstract interests and fantasies and disinhibition of impulses. This category involves children with a pronounced conflict of behavior; rapid exhaustion in any activity; weakness of emotional attachments; expressed selectivity in contacts; with the presence of unmotivated fears; unaddressed speech, which is not aimed at the interlocutor; in a gaze going "through" a person. Nosological qualification of this group has certain difficulties - we can talk both about sluggish schizophrenia and autistic psychopathy. In the fourth group, the main pathopsychological syndrome is increased vulnerability when interacting with others which manifests itself in a bad mood, overvalued fears, quiet slow-moving game; in the growth of fearfulness and stiffness at the slightest change in the usual stereotype, in retardation, motor awkwardness, lack of confidence in movements, in the need for a positive assessment and empathic support; in intermittent visual contact; in symbiotic relationship with beloved ones. Speech may be fading. From nosological point of view, this type may be a special form of a constitutional developmental anomaly (Kanner syndrome), and with mild severity it may be a form of Asperger's autistic psychopathy.

\section{Discussions}

Today, the prevailing point view says that, apart from the classic forms of Kanner autism, there are also disorders that share many characteristics with the basic syndrome without a full set of criteria. A whole group of diseases is sometimes referred to as "autism spectrum disorders". Wing (1981) was among the first researchers who wrote about this, describing it as the "spectrum of autism". For some period of time, childhood schizophrenia and childhood psychosis were also understood as sections, areas of autism and autism spectrum disorders. However, today childhood schizophrenia is studied as a separate disorder, which is very rare and different from autism. Gilbert and Peters (2005) include the following diseases to autism spectrum disorders: Asperger syndrome, childhood disintegrative disorder, diseases similar to autism, autistic features.

Emphasizing the importance of the underlying causes of autism, modern international diagnostic systems DSM-IV, ICD-10 distinguish psychodynamic, environmental, organic and neurological causes biological disorders, biochemical pathology and genetic factors, characterizing childhood autism (Kanner syndrome) as a pervasive developmental disorder which is clinically identified as a disorder (deviation or delay) in the development of attention, reality testing and in the development of social, linguistic and motor behavior and includes three main blocks of diagnostic criteria of development and behavior: violation of social interaction, violation of communication skills and imagination, and significant reduction in interests and activity. As the most important criteria for the diagnosis of autism, the researchers emphasize the time of appearance of the first symptoms at the age of not later than 30 months, fundamental inadequacy of reactions to the environment stimulus, deficiency of speech development, and in case of developed speech skills - its originality, for example, delayed echolalia, metaphorical language, distorted use of personal pronouns, quirkiness reactions to the environment: resistance to changes, peculiar, interested attitude to some animate or inanimate objects, the absence of delusions and hallucinations, associative weakness and incoherence as in schizophrenia.

According to the criteria of the International Statistical Classification of Diseases and Related Health Problems of the 10th edition (ICD-10), adopted by the World Health Organization (WHO), autistic 
spectrum disorder includes: qualitative disorders in social interaction, qualitative disorders in the ability to communicate and limited repetitive and stereotypical patterns of behavior, interests, and activities.

In Russia, the ICD-10 classification is the most common one, but an agreement has already been reached between the World Health Organization (WHO) and the US National Institute of Mental Health, according to which the high compatibility of the DSM-5 and the International Classification of Diseases ICD-11 should be achieved, with edition number 11 currently being developed by the WHO.

As of today, in terms of describing autism spectrum disorders, DSM-5 provides the most relevant and complete methodology for understanding the behavior of a child with autism and describing symptoms and basic levels of severity of autism spectrum disorders. All components of autism spectrum disorders are distributed in DSM-5 into two main sections (the so-called "autism dyad"): (A) lack of social communication and social interaction and (B) limited, repetitive patterns of behavior, interests, or activities. According to modern American Diagnostic and Statistical Manual of Mental Disorders of the fifth edition (DSM-5), the following 4 disorders from the previous edition (DSM-IV) (autistic disorder; Asperger syndrome; childhood disintegrative disorder; pervasive developmental disorder not otherwise specified (PDD-NOS) were combined into one - autism spectrum disorder.

According to The International Classification of Diseases of the tenth revision (ICD-10), autism spectrum disorders are included in the group "common developmental disorders". The diagnosis of autism spectrum disorder is absent in ICD-10. In the 2018 edition of ICD-11, a new diagnostic unit called "autism spectrum disorder" appeared. In the ICD-11, autism spectrum disorder is divided into subtypes with indication of the presence / absence of intelligence disorder and indication of a person's ability to use the so-called "functional language", that is, as a mean to express personal needs or desires.

Thus, early and differential diagnosis of autism allows to determine the path of mental development and social adaptation of a child with autistic manifestations, since the timely start of psychological and pedagogical remedial work in combination with drug therapy (if absolutely necessary) contributes to the maximum mobilization of the child's available mental activity resources including emotional, cognitive, motor spheres.

The most important area of structural analysis of autism content is associated with the study of the peculiarities of the mental development of children in various forms of autism manifestations. This is evidenced by the studies of such authors as Bashina (1999), Kagan (2015), Wing (1981), Gilbert \& Peters (2005), Lebedinskaya, Nikolskaya, \& Baenskaya (2007) and others.

Lebedinskaya, Nikolskaya, \& Baenskaya (2007) identify two main pathogenic factors that manifest themselves from the very moment of birth of an autistic child: impaired ability to actively interact with the environment and lowering the threshold of affective discomfort in contacts with the world. According to the author, the first factor manifests itself through a decrease in vitality and through difficulties in organizing active relations with the world. At first, it can manifest itself as a general lethargy of a child who does not require attention to oneself; such children surprise their parents by the lack of curiosity and interest in anything new. Child's activity is unevenly distributed; they face great difficulties when trying to organize their behavior or to focus their attention. The second factor, as the author believes, manifests itself as a painful reaction to ordinary sound, color, light, or touch - such children do not take a "ready position" when taken in their parents' arms, they can react violently to certain sounds, refuse to wear clothes of a certain color, or made of a specific material, or "taboo" some colors when drawing. The second factor also reveals itself in increased vulnerability when contacting with other people - for example, these children are characterized by rapid fatigue, satiation of communication, even those that are pleasant 
for them. Keeping visual contact with a child is possible for a very short period of time. In addition, children tend to "get stuck" in unpleasant impressions, form tough selectivity in communication, create a system of prohibitions and fears.

Autistic children are also characterized by stereotype caused by their limited capability of flexible interaction with the environment and the ability to adapt only to sustainable forms of life. In order to raise vitality and silence discomfort, children often use compensatory autostimulations (for example, monotonous movements, swaying, and manipulations with various objects). When trying to include, involve such a child in the interaction, there is a noticeable increase in anxiety, insecurity, tension, and often increased auto-stimulation. Autistic children more easily communicate with adults - they give them preference, up to the establishment of a symbiotic relationship, but this communication often has a tinge of dependence and subordination, and may be outwardly framed by suspicion and wariness. Attitudes toward people as objects that carry certain properties and functions explain the attachment of children not to individuals, but to certain places and environment while the desire to feel confidence explains stereotyped behavior.

Autistic children often have problems with the formation of self-service skills, with the development of normal activities with objects necessary for life. Such children make awkward movements when doing something useful with objects around them - it is seen both in big body movements and in fine hand motor skills, but at the same time, their movements can be surprisingly precise when it comes to stereotypical, "ritual" movements or autostimulation.

Based on the analysis of the cognitive sphere of preschoolers, Akhmedova \& Feofanov (2017) came to the conclusion that the development of thinking in this category of children is associated with difficulties in voluntary learning and purposeful resolution of actual problems. There are difficulties in generalization and limitations in the awareness of the subtext of what is happening around, onedimensional, literal understanding of things. It is difficult for such child to comprehend the development of the situation in time, to part cause and effect in the sequence of events. The lack of general and mental tone combined with increased sensory and emotional sensitivity causes an extremely low level of active attention. There is a lack of attention of the child to the surrounding objects of the environment from the very early age. Talking about the development of perception, the authors note violations of orientation in space and time, distortion of the holistic picture of the real world and isolation of individual sensations, sounds, colors, and forms that seem significant for the child. Children tend to make stereotypical pushing moves on an ear or eye, play with their fingers or play with light.

Speech development is also quite original. Children do not use it (or underuse it) for communication purposes. The pace of speech development is uneven and asynchronous. Phrasal speech is formed with a delay, often without a prior babbling period and the stage of the emergence of individual words and is characterized by the absence of pictorial and onomatopoeic words at an early age.

Vasyagina, Grigoryan, \& Kazyaev (2018) emphasize that absolutely all people with autism have impaired communication, but the degree and the nature of these disorders may vary significantly. Problems with speech, namely the communicative function, often become one of the main causes of severe behavioral disorders in children with autism. The authors note that over the past 20 years, science and practice have progressed in the area of understanding of violations of social interaction and communication in children with autism. This is due to the fact that in the main diagnostic reference books (DSM-IV and ICD - 10), the parameters of social interaction and communication disorders act as key markers of ASD. This fact facilitates the rehabilitation work with children of this category. 
Uvarova (2016) also focuses on the fact that the most autistic spectrum disorders affect children's speech development. The author identifies several areas in which qualitative violations of the communication formation in preschool children manifest themselves. These include: delay or complete absence of spontaneous speech without any attempts to compensate it with gestures or facial expressions (there may be no communicative gurgling in the first year of life); inability to start or maintain a conversation (at any level of speech development); the presence of repetitions and stereotypes; lack of spontaneous role-playing games and imitative games at a younger age. The distorted sequence of speech development can also manifest itself in the early formation of monologue speech without the preceding dialogue. Speech is characterized by the inflexibility and "mechanistic" or "parrot-like" nature. It often sounds like a stump one. One of the most prominent characteristics of the speech of an autistic child is echolalia, often delayed - repetition of a phrase heard somewhere else out of touch with the actual situation. Agrammatisms in speech are also very obvious: phrases are often formed with violation of the usual word order and sound like a "foreign language". Sometimes children use certain verbs in an indefinite form or in the imperative mood especially when they express their desires or tend to draw attention to themselves for the fulfillment of any request. The speech is also characterized by a long absence of the pronoun "I". This is probably due to the inability of a child to feel oneself in the world personally, that is, as a subject and as an object at the same time. In spontaneous speech they may often call themselves by name. Words like "yes" and "no" are also mastered by a child with a delay ("no" is mastered more easily).

Exploring the emotional-volitional, cognitive spheres, Inevatkina, Page, \& Lazareva (2018) note that most of the subjects have a break from reality, isolation from the world, the absence or paradox of reactions to external influences, passivity and over-exposure in contacts with the environment. Emotions are weakly expressed and the behavior is characterized by stereotypical reactions. There are also deficiencies in nonverbal communicative behavior used in social interaction; there is a lack of eye contact, no facial expressions and gestures. In addition, subjects are not able to independently determine the emotional state of another person and so not show interest in the emotional state of another person. Only part of preschoolers with autism spectrum disorders showed behavioral acts characterized by attempts to maintain interaction with the experimenter. The subjects participate in the interaction initiated by the adult using the assistance offered to them for the execution of the task. At the same time, there are specific behavioral reactions associated with the need to follow the rules or patterns.

Kagan (2015) notes regular phasing in the formation of attitudes towards the environment in an autistic child which develops in a slow and asynchronous way: attitude towards the world of objects, separation of a person from the world of objects, attitude to another person as a subject and, finally, identification of oneself as a personality. A child can go the way of one's personal growth to the end, but he can "get stuck" at some of the stages. As the experience of researchers of this issue shows, only a few autistic children manage to reach the level of personal identification.

In the development of the thinking of children with autism, the researchers note difficulties with voluntary learning, purposeful resolution of real-life tasks. Experts emphasize difficulties with symbolization, with transfer of skills from one situation to another, difficulties with generalization, onedimensional, literal interpretations of what is happening around.

Undoubtedly, children have many behavioral problems. The most obvious one is an active negativism - the refusal from team activities, training, and situations of arbitrary organization. Manifestations of negativism may be accompanied by increased autostimulation, physical resistance, 
aggression, self-aggression, and "going into oneself" even more (from the outside it may seem that the child cannot see or hear anything).

Another huge problem is the fears of a child that may seem unclear to others, since they are directly related to the increased sensibility of such children (for example, children may be afraid of household electrical appliances that produce harsh sounds, water noise, darkness or bright light, closed doors, high-necked clothes etc.) Very often, this fear can become the cause of aggression, which most often is not directed at anyone specifically. The term "generalized aggression" is used to describe the aggression directed at the whole world and its explosions can be intense and destructive. Extreme manifestation of the despair of such children is self-aggression, which often represents a real threat to their lives and health.

\section{Conclusion}

At the present stage, further psychological and pedagogical study of the phenomenon of autism is associated with the analysis of existing practices and the search for new, most effective models and technologies of dealing with childhood autism. The analysis of the existing practices conducted by Don (2017) showed that currently the following models of education for children with autism exist: an inclusive group / class (a child with autism is included in the general educational group / class with normotypic peers); inclusive group / class using the technology of the resource class (a child with autism is included in the general educational group / class with normal peers, individual work is carried out in the resource class); integrated group / class (a child with autism is included in a group / class of compensatory orientation with children having other developmental features); Specialized group / classroom for children with autism and home-based learning. The prerequisites for the implementation of these models are: the creation of a specially organized environment in the educational organization allowing to compensate for the missing skills and facilitate the adaptation of the child, psychological and pedagogical support of all subjects of inclusive (special) education specialists of a different profile (pedagogical psychologist, speech therapist, speech pathologist). The substantive component of these models includes working with a child with autism in order to facilitate its adaptation to society and minimize behavioral difficulties when interacting with adults and peers, working with the family as an active participant in the educational process, working with pedagogical team aimed at raising awareness on the specifics of education of this category of children, on the formation of their special competencies, allowing not only to understand and take into account the peculiarities of children with autism, but also to learn methods that will allow to develop skills of social interaction, to eliminate undesirable forms of behavior (Vasyagina, Grigoryan, \& Kazayeva, 2018)

Morozov (2002) conducted the study devoted to evaluating the effectiveness of practices of working with people with autism. Among the most common approaches, the author identifies early intensive behavioral interventions based on the principles of ABA therapy; the main method of teaching is the method of discrete samples. The next approach is based on the Early Start Denver Model (ESDM) and early childhood developmental, individual difference, relationship-based model (DIR / Floortime). The basis of ESDM is formed by strategies that transform almost any daily activities, procedures and regime points into effective techniques of gaming interaction, communication and learning. The main task is to accelerate the development of a child through the development of social communication, social attention and motivation and the ability to establish interpersonal interaction. The goals of the DIR model are to create a healthy foundation for social, emotional, and intellectual skills. "D" describes development from the point of view of an individual and means giving every person the opportunity to be respected and 
guided by in one's personal development path; "I" describes the unique ways in which each person accepts, regulates, reacts and understands the world. "R" describes how relationships fuel development, i.e. humans are social beings, and relationships are the key to our human development. DIR uses the key affective (emotional) aspect of this relationship to boost development. DIR Floortime (Floortime) is the application of the DIR model in practice, it is a special method that allows to both follow the natural emotional interests of a child (to lead), and at the same time to encourage the child to increasingly master social, emotional and intellectual skills. While the DIR model helps to understand and contribute to positive development of all children, DIR and DIR Floortime are most often used with children who have problems with education, social and emotional state, mental health and / or development.

The results of Morozov's study confirm the opinion of Rutter (1985), Baron-Cohen (2002) that autism is characterized by the absence of significant changes in treatment results and the effectiveness of modern correction methods is moderate or even low, which leads to a poor level of education and upbringing of children with autism (Morozov, 2002) and, as a result, to poor adaptation and socialization.

\section{References}

Akhmedova, I. E., \& Feofanov, V. N. (2017). Correctional work on development of cognitive functions in the preschool children having frustration of an autistic range. Socialization and rehabilitation in the modern world. Collection of scientific articles. Science and education: keeping the past, we create the future, 249-255.

Asperger, H. (1968). On the differential diagnosis of early infantile autism. Acta Paedopsychiatrica: International Journal of Child \& Adolescent Psychiatry, 35(4-8), 136-145.

Baron-Cohen, S. (2002). The extreme male brain theory of autism. Trends in cognitive sciences, 6(6), 248254.

Bashina, V. M. (1999). Autism in the childhood. Moscow: Medicine.

Bashina, V. M., Krasnoperova, M. G., \& Simashkova, N. V. (2003). Classification of frustration of an autistic range at children. Autism and violations of development, 2, 2-9.

Don, (2017). Conditions of education of the children of preschool age having RAS in group of short-term stay. Autism and violations of development, 15(4), 16-25. doi: 10.17759/autdd.2017150403

Gilbert, K. \& Peters, T. (2005). Autism. Medical and pedagogical influence. Moscow: VLADOS center.

Inevatkina, B., Page, E., \& Lazareva, N. V. (2018). To a question of the organization of psychology and pedagogical escort of preschool children with frustration of an autistic range. Problems of modern pedagogical education, 58 (4), 104-107.

Isaev, D. N., \& Kagan, V. E. (1973). Autichesky syndromes at children and teenagers: mechanisms of disorders of behavior. Pathological violations of behavior. Leningrad: Leningrad Pediatric medical institute.

Kagan, V. E. (1981). Autism at children. Leningrad: Medicine.

Kagan, V. E. (2015). Autyata. To parents about autism. St. Petersburg: St. Petersburg.

Kanner, L. (1943). Autistic disturbances of affective contact. Nervous child, 2(3), 217-250.

Lebedinskaya, K. S., Nikolskaya, O. S., \& Bayenskaya, E. R. (2007). Children with communication violations: early children's autism. Moscow: VLADOS.

Medvedev, S. E. (2011). The synergetic bases of rehabilitation of children and adults with autichesky frustration. Medical psychology in Russia, 2. Retrieved from http://medpsy.ru

Mikirtumov, B. E., \& Zavitaiev, P. Y. (2012). Autism: background and modern view. St. Petersburg: Piter. 
Morozov, S. A. (2002). Detskii autism i osnovy ego korrektsii [Children's autism and the basics of intervention]. Moscow: Signal.

Mnukhin, S. S., Zelenskaya, A. E., \& Isaev, D. N. (1967). About a syndrome of early children's autism, or about Kanner's syndrome at children. The magazine of neuropathology and psychiatry of S.S. Korsakov, 10, 56-78.

Nissen, M. J., Willingham, D., \& Hartman, M. (1989). Explicit and implicit remembering: When is learning preserved in amnesia?. Neuropsychologia, 27(3), 341-352.

Rutter, M. (1985).The treatment of autistic children. Journal of Child Psychology and Psychiatry, 26, 193214.

Schmidt, S. (1978). Der Radikale Konstruktivismus: Ein neues Paradigma im interdisziplinaren Diskurs. Der Diskurs des Radikalen Konstruktivismus. Frankfurt am Main: Suhrkamp.

Schopler, E., \& Mesibov G. B. (1988). Diagnosis and assessment in autism. New York: Plenum Press.

Schopler, E., Van Bourgondien, M. E., \& Bristol M. M. (1993). Preschool issues in autism. New York: Plenum Press.

Schopler, E., Short, A., \& Mesibov, G. B. (1989). Relation of behavioral treatment to "normal functionning": Comment on Lovaas. Journal of Consulting and Clinical Psychology, 57, 162-164.

Simashkova, N. V. (2006). Psychotic forms of atypical autism at children's age. The magazine of neuropathology and psychiatry of S.S. Korsakov, 106(10), 11-18.

Sukhareva, G. E. (1974). Lektsii po psikhiatrii detskogo vozrasta: Izbrannye glavy [Lectures on children's psychology: Selected chapters]. Moscow: Meditsina.

Tiganov, A., \& Bashina, V. M. (2005). Modern approaches to understanding of autism in the childhood. Magazine of neuropathology and psychiatry, 105(8), 4-13.

Uvarova, T. B. (2016). The preschool child with frustration of an autistic range in the conditions of kindergarten of the combined look. Konferentsium ASOU: collection of scientific works and materials of scientific and practical conferences, 4, 2389-2393.

Vasyagina, N. N., Grigoryan, E. N., \& Kazayeva, E. A. (2018). Psychology and pedagogical aspects of rehabilitation of children with frustration of an autistic range in the conditions of preschool education. National psychological magazine, 2(30), 92-101.

Wing, L. (1981). Asperger's syndrome: a clinical account. Psychological medicine, 11(1), 115-129. 